\title{
Calculation of the Chilling Requirement for Air Conditioning in the Excavation Roadway
}

\author{
Yueping Qin ${ }^{1}$, Song Kong ${ }^{1, *}$, Wei Liu ${ }^{1}$, Zhenjun Jiang ${ }^{2}$ and Jiansong Wu ${ }^{1}$ \\ ${ }^{I}$ School of Resources and Safety Engineering, China University of Mining and Technology (Beijing), Beijing 100083, China \\ ${ }^{2}$ State development and investment corporation, Beijing 100034, China \\ Received 18 May 2015; Accepted 30 October 2015
}

\begin{abstract}
To effectively improve the climate conditions of the excavation roadway in coal mine, the calculation of the chilling requirement taking air conditioning measures is extremely necessary. The temperature field of the surrounding rock with moving boundary in the excavation roadway was numerically simulated by using finite volume method. The unstable heat transfer coefficient between the surrounding rock and air flow was obtained via the previous calculation. According to the coupling effects of the air flow inside and outside air duct, the differential calculation mathematical model of air flow temperature in the excavation roadway was established. The chilling requirement was calculated with the selfdeveloped computer program for forecasting the required cooling capacity of the excavation roadway. A good air conditioning effect had been observed after applying the calculated results to field trial, which indicated that the prediction method and calculation procedure were reliable.
\end{abstract}

Keywords: excavation roadway, temperature field of surrounding rock, air temperature forecasting, chilling requirement

\section{Introduction}

With the increase of mining depth, the work environment in coal mine is inevitably faced with the overrun of air temperature because of high geotemperature. The thermal hazard in excavation roadway is especially severe due to the geological and production factors, such as the limited space, the production concentration and etc. The climatic conditions of high temperature and humidity threaten the health of workers and the safety production in mines [1], [2]. While working in the underground environment with high temperature and humidity, the thermal equilibrium of human body might be seriously undermined. Thus the workers are susceptible to suffer heat stroke, heat cramps, heat exhaustion and heart diseases. Moreover, the rate of accidents is likely to increase while the labor productivity to decrease significantly in contrast [3].

For the excavation roadway with high temperature, the most widely used approach improving the climate conditions is to adopt air conditioning measures, since the nonrefrigeration measures such as increasing the amount of air flow separately do not perform well. Therefore, the calculation of chilling requirement becomes the critical problem for air conditioning design in excavation roadway [4], [5]. As shown in Figure 1, (a) is for the heading area of the excavation roadway, (b) is for the excavation roadway.

* E-mail address: phoenixks@live.cn ISSN: 1791-2377 @ 2015 Kavala Institute of Technology. All rights reserved.

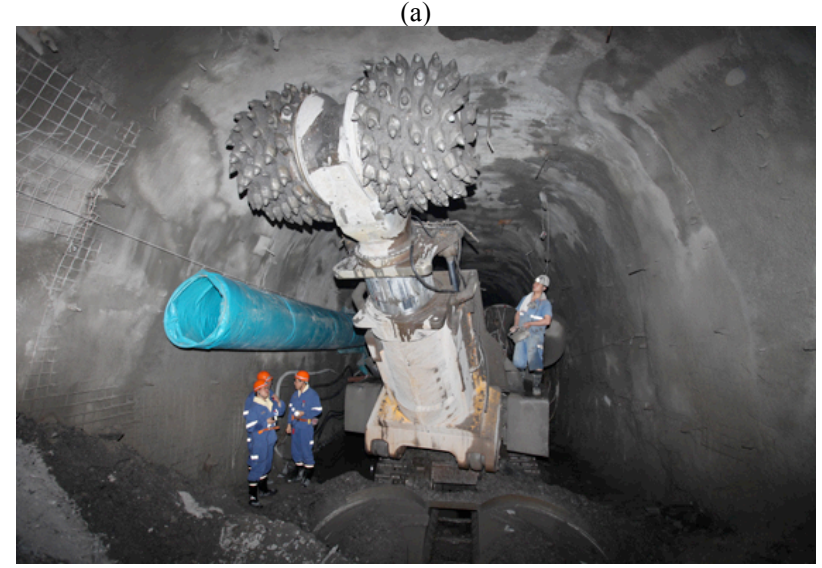

(b)

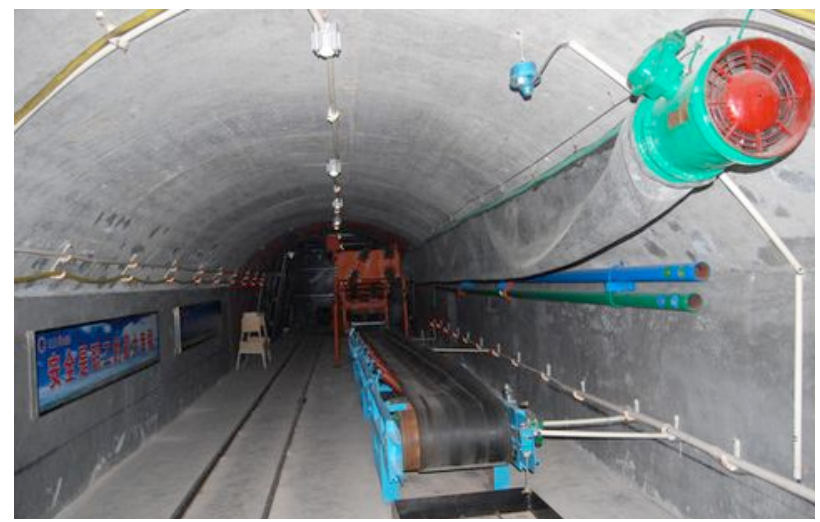

Fig.1. The excavation roadway in coal mine (a).is the heading area (b) is the excavation roadway. 


\section{Related background}

The research on air conditioning in the excavation roadway is mainly about two aspects: scientific prediction of the climate conditions and reasonable formulation of the air conditioning measures. The prediction of climate conditions is the basis of air conditioning. No matter what air conditioning measures adopted, it is necessary to analyse and evaluate the thermal hazard status of the excavation roadway with scientific theories and calculation methods, and to forecast the implementation effect of the air conditioning measures. Otherwise, the formulation of air conditioning measures is blind, and it is difficult to achieve the expected purpose. At present, because of lacking scientific and standardized theories and methods, the chilling requirement of underground workplaces could not be calculated reasonably. Thus, the design of air conditioning in the deep mines with high temperature is absence of grounds, and a large number of mine-conditioning systems do not achieve the expected effect in China. In conclusion, the research on the scientific calculation of chilling requirement in excavation roadway is of great theoretical and realistic significance.

Numerous scholars have studied the theories of air temperature prediction and chilling requirement calculation in mines, and the influence of thermodynamic parameters related to the chilling requirement [6]. The research is focused on the prediction of air temperature in throughroadway, and few studies have been published specially on the calculation theory of air temperature and chilling requirement in blind tunnel. Starfield et al. preliminarily studied the heat and moisture transfer in partly wet airway [7]. Uchino et al. analysed the influence of moisture on the underground environment in mines, and proposed a new practical method for calculation of air temperature and humidity along wet roadway [8]. Subsequently, Uchino et al. improved the practical method proposed in 1986 for calculation of air temperature [9]. Hu calculated the air temperatures along ventilation ducts in the driving face [10]. Sasaki et al. proposed the analytical system for ventilation simulators with skyline modal pressure method and practical estimate system for underground mine air-conditioning [11]. $\mathrm{Qu}$ et al. applied the self-developed computer programs of reasonable arrangement of mining faces in hot mine, and calculated the air temperatures and chilling requirement in working places [12] , [13]. Bluhm et al. addressed the optimum cooling systems required for the mines which virgin rock temperatures were in excess of $60^{\circ} \mathrm{C}$, on the basis of calculation of the chilling requirement [14]. Gao et al. calculated and predicted the climatic conditions in developing roadway with forcing auxiliary ventilation system [15]. Subsequently, Gao et al. investigated the thermal environment at working face of driving airway by numerical simulation [16]. Ii carried out the research on the heat-calamity forecast model in drivage roadway of deep shaft [17]. Qi analysed the heat and humidity exchange in the roadway and adopted FLUENT to simulate the thermal environment [18]. Guo et al. proposed a back-analysis algorithm of cooling load in deep mines, and calculated the chilling requirement of working face using the thermodynamics and enthalpy difference [19]. Ji et al. analysed the heat transfer characteristics of driving face in heat harm mine by ANSYS numerical simulation test and similar simulation experiment [20].

However, there are plenty of problems of the current calculation methods [21]. The wall temperature of the end surface in excavation roadway is normally assumed as the initial temperature of surrounding rock in conventional methods. Then the heat dissipating capacity of the surrounding rock is calculated with the Newton's law of cooling or the intensity formula of heat emission. However, the wall temperature is actually not equal to the initial temperature of the surrounding rock, and the unstable heat transfer coefficient between the air flow and the surrounding rock is obtained not accurately enough by means of given value or empirical formula. It cannot truly reflect the characteristics of the temperature field of surrounding rock in the excavation roadway with moving boundary. The air temperature in the excavation roadway is generally assumed to change linearly in conventional methods. Based on this, the temperature inside and outside the air duct is calculated. However, the correlational research indicates that the air flow inside and outside the air duct is coupling with each other and both temperatures change nonlinearly. The conventional methods can not accurately combine the laws of the heat dissipation from surrounding rock and the coupling effect of air flow inside and outside the air duct in the excavation roadway. Due to the low accuracy of air temperature prediction, there is no perfect method for the calculation of chilling requirement.

In this paper, the temperature field of surrounding rock is primarily to be calculated. Then the differential calculation model of air flow temperature in the excavation roadway is to be established, according to the coupling effect and the temperature nonlinear change of the air flow inside and outside the air duct. Based on this, the calculation program of air temperature and chilling requirement in the excavation roadway is to be edited. Using the self-developed computer program to calculate the air temperature and chilling requirement thus provide the scientific guidance for the formulation of the air conditioning measures to effectively improve the climate conditions in the excavation roadway.

\section{Methodology}

\subsection{Calculation of the temperature field of surrounding} rock with moving boundary

3.1.1 Mathematical model of the temperature field of surrounding rock

In order to calculate the temperature field of surrounding rock with moving boundary in the excavation roadway, it is necessary to make some assumptions. It is assumed that the temperature field is axisymmetric without inner heat source, the cross section of the excavation roadway is rounded, the surrounding rock is homogeneous and isotropic, and the heat exchange conditions on the end face and its circumference are consistent with the roadway. The working face is assumed to propel at a constant velocity, thus the temperature does not change with time anywhere in the temperature field of surrounding rock. In addition, the temperature of wall surface and air flow in the excavation roadway does not change with time as well.

With the above hypotheses, the temperature field is simplified along the center line of the roadway as shown in Figure 2. With the introduction of the coordinate system moving along with the working face, the unsteady heat conduction differential equation in the original coordinate is converted to the steady state one. As shown in Figure 2, it is convective heat transfer between air flows and surrounding rock on the wall of the end face and the excavation roadway, thus $\Gamma_{1}$ and $\Gamma_{2}$ are the third boundary conditions. The heat discharge along the axial direction of the surrounding rock 
from a certain distance behind the working face is approximately zero, thus $\Gamma_{3}$ can be considered as the adiabatic boundary. The temperature of the surrounding rock beyond a certain distance from the wall is approximately equal to the original rock temperature and can be used as the boundary of temperature field. Thus $\Gamma_{5}$ is the first boundary condition and the temperature is equivalent to the original rock temperature. The simultaneous differential equations composed of Eqs. (1) and (2) are the mathematical description of the temperature field of surrounding rock in the moving coordinate system [22], [23].

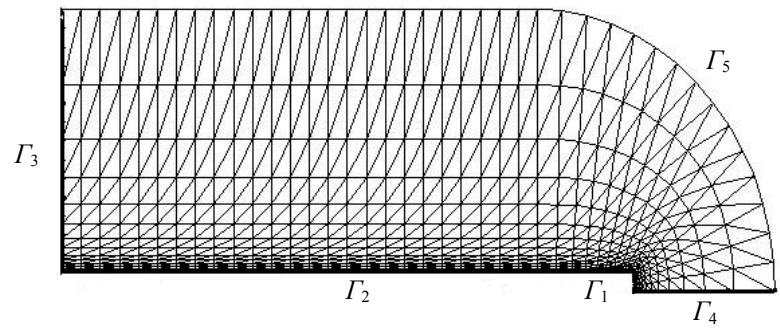

Fig.2. Meshing generation of the temperature field of surrounding rock in the excavation roadway

$$
\begin{gathered}
\frac{\partial^{2} T}{\partial x^{2}}+\frac{\partial^{2} T}{\partial r^{2}}+\frac{1}{r} \frac{\partial T}{\partial r}=\frac{-v}{a} \frac{\partial T}{\partial x} \\
\left\{\begin{array}{c}
\left.\lambda \frac{\partial T}{\partial x}\right|_{\Gamma_{1}}=\alpha\left(T_{\Gamma_{1}}-T_{f}\right) \\
\left.\lambda \frac{\partial T}{\partial r}\right|_{\Gamma_{2}}=\alpha\left(T_{\Gamma_{2}}-T_{f}\right) \\
\left.\lambda \frac{\partial T}{\partial x}\right|_{\Gamma_{3}}=0 \\
\left.\lambda \frac{\partial T}{\partial r}\right|_{\Gamma_{4}}=0 \\
\left.T\right|_{\Gamma_{5}}=T_{g u}
\end{array}\right.
\end{gathered}
$$

where $T$ is the temperature of surrounding rock, ${ }^{\circ} \mathrm{C} ; v$ is the advance rate of working face, $\mathrm{m} / \mathrm{s} ; a$ is the thermal diffusivity of surrounding rock, $\mathrm{m}^{2} / \mathrm{s} ; T_{\Gamma 1}$ and $T_{\Gamma 2}$ are the wall temperatures on boundary $\Gamma_{1}$ and $\Gamma_{2}$ respectively, ${ }^{\circ} \mathrm{C} ; \lambda$ is the thermal coefficient of surrounding rock, $\mathrm{W} / \mathrm{m} \cdot{ }^{\circ} \mathrm{C} ; \alpha$ is the convective heat-transfer coefficient, $\mathrm{W} / \mathrm{m}^{2} \cdot{ }^{\circ} \mathrm{C} ; T_{f}$ is the air temperature in the excavation roadway, ${ }^{\circ} \mathrm{C} ; T_{g u}$ is the initial temperature of surrounding rock, ${ }^{\circ} \mathrm{C}$.

\subsubsection{Meshing generation}

According to the temperature field of surrounding rock in the excavation roadway, the computational area is divided with the geometric proportion increasing size of the grid from the wall surface to the rock in deep. In addition, the grid density is appropriately increased on the end face and the wall surface in the excavation roadway as shown in Figure 2 [22], [24].

The mathematical model of the temperature field of surrounding rock is dispersed with the finite volume method [25], [26] [27]. Based on this, the calculation program is edited. Therefore, the unstable heat transfer coefficient for the prediction of air temperature is calculated with the program.
3.2 Calculation model of the chilling requirement in the excavation roadway

\subsubsection{Geometric model}

Air flow is inhaled into air duct by the local fan, after heat and moisture exchange with the air cooler arranged in the roadway, and then be sent to the working face. Along with the air flow inside air duct flowing to the heading face, the air flow outside air duct flows the other way. Heat and moisture exchange of the air flow inside and outside air duct occur, and HME between the air flow and the surrounding rock exist as well. The temperature of air flow is decided by the heat sources during the flow process. For the convenience of calculation, the short length with complex heat exchange from the tunnel entrance to the ventilation roadway is considered as an entirety of cross-section. According to the excavation roadway with air conditioning measures, the ventilation system is simplified as shown in Figure 3. The calculation model is divided into seven sections. Section 1 is the local fan entrance. Section 2 is the air duct entrance. Section 3 is the excavation roadway entrance. Section 4 is the air cooler entrance. Section 5 is the air cooler exit. Section 6 is the air duct exit. Section 7 is the end face of the excavation roadway. The spacing from section 2 to section 4 and from section 5 to section 7 is $L_{2}, L_{3}$, $L_{4}$ and $L_{5}$ respectively.

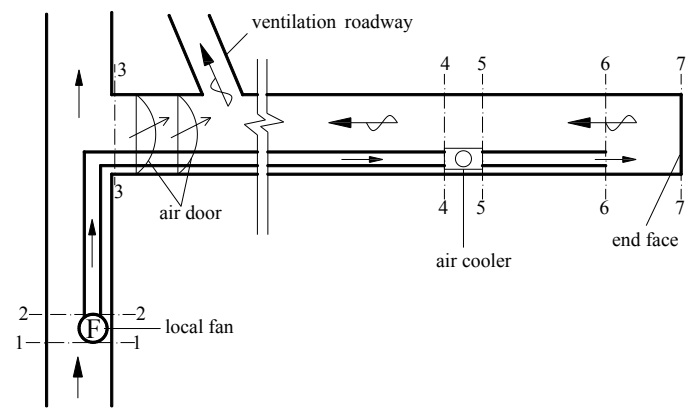

Fig.3. Schematic diagram of the ventilation system in the excavation roadway with air conditioning measures

\subsubsection{Prediction model of the air temperature}

The characteristics of the calculation of air temperature in the excavation roadway are described as following: after heat and moisture exchange with the air cooler which performs as a negative heat source, the thermodynamic parameters such as the humidity and the moisture content of the air flow at the air cooler exit change comparing to the air at the local fan entrance. Because the length of air-cooler is way smaller than air duct and roadway, the size of air cooler can be ignored when calculating the temperature of the air flow outside air duct. Thus, thermodynamic parameters of the air flow at section 4 and section 5 are considered to be identical. Since the environmental temperature has to be satisfied the 'Coal Mine Safety Regulations', the temperature of the air flow at section 6 should be lower than $26^{\circ} \mathrm{C}$ after absorbing heat from the heat sources in heading face. The internal thermal variation of the air cooler can be ignored, and the chilling requirement is determined according to the prediction of the air enthalpy in front and back of the air cooler.

The basic rules of the prediction theory of air temperature are analyzed as following.

(1) The energy-balance equation of the air flow at section 2 and section 3 is established separately referring to the corresponding content of the references [5], [21]. The thermodynamic parameters of the air flow inside air duct at 
section 3 are determined by the thermodynamic parameters at section 2 and the HME of the air flow between section 2 and section 3 .

(2) Section 3 to section 6 in the excavation roadway can be seen as an entirety. Because the air temperatures inside the air duct from section 2 to section 4 are higher than that of section 1, and the leakage of air flow only happens from the inside to the outside, the moisture contents of the air flow inside the air duct from section 1 to section 4 are equal. Because the air temperature inside the air duct at section 5 after flowing through the air cooler is generally less than the dew-point temperature at section 1 , the moisture contents of the air flow inside the air duct from section 5 to section 6 are less than that of section 1.

$\mathrm{X}$ axis is built along the roadway, and the coordinate origins from section 3 and points to section 6 . The differential segment $d x$ is taken from section 3 to section 4 , hence the energy-balance equations of the air flow inside and outside air duct can be deduced as:

$$
\begin{aligned}
& M C_{p} d t_{i}=\left(t_{o}-t_{i}\right) k \pi D d x-M g \sin \theta d x \\
& M\left(C_{p}+r \frac{130.93 \varphi_{o}}{B-3066.8}\right) d t_{o}=\left(k \pi D+\frac{\rho c}{1+d_{i 14}} C_{p}\right)\left(t_{i}-t_{o}\right) d x \\
& +\left(\frac{\rho c}{1+d_{i 14}} r d_{i 14}-M g \sin \theta\right) d x+k_{\tau} U\left(t_{g u}-t_{o}\right) d x \\
& -\frac{0.622 \times 210.5}{B-3066.8} \cdot r\left(\frac{\rho c}{1+d_{i 14}} \varphi_{o}+M \varphi^{\prime}\right){ }_{o} d x \\
& +\frac{0.622 \times 2066.5}{B-3066.8} r\left(\frac{\rho c}{1+d_{i 14}} \varphi_{o}+M \varphi^{\prime}\right) d x
\end{aligned}
$$

Similarly, the differential segment $d x$ is taken from section 5 to section 6 , the energy-balance equations of the air flow inside and outside air duct can be deduced as:

$$
\begin{aligned}
& M\left(C_{p}+r \frac{130.93 \varphi_{o}}{B-3066.8}\right) d t_{o}=\left(k \pi D+\frac{\rho c}{1+d_{i 56}} C_{p}\right)\left(t_{i}-t_{o}\right) d x \\
& +\left(\frac{\rho c}{1+d_{i 56}} r d_{i 56}-M g \sin \theta\right) d x+k_{\tau} U\left(t_{g u}-t_{o}\right) d x \\
& -\frac{0.622 \times 210.5}{B-3066.8} \cdot r\left(\frac{\rho c}{1+d_{i 56}} \varphi_{o}+M \varphi^{\prime}\right)_{o} d x \\
& +\frac{0.622 \times 2066.5}{B-3066.8} r\left(-\frac{\rho c}{1+d_{i 56}} \varphi_{o}+M \varphi^{\prime}\right) d x
\end{aligned}
$$$$
d_{i}=0.622 \frac{\varphi p_{s o}}{B-\varphi p_{s o}} \approx 0.622 \frac{\varphi(210.5 t-2066.5)}{B-3066.8}
$$

where $M$ is the mass flow rate of dry air, $\mathrm{kg} / \mathrm{s} ; C_{p}$ is the specific heat at constant pressure, $\mathrm{kJ} /\left(\mathrm{kg} \cdot{ }^{\circ} \mathrm{C}\right) ; t_{i}$ and $t_{o}$ are the air flow temperatures inside and outside air duct respectively, ${ }^{\circ} \mathrm{C} ; k$ is the heat transfer coefficient of the air duct, $\mathrm{kW} /\left(\mathrm{m}^{2} \cdot{ }^{\circ} \mathrm{C}\right) ; D$ is the diameter of the air duct, $\mathrm{m} ; \mathrm{g}$ is the gravitational acceleration, $\mathrm{m} / \mathrm{s}^{2} ; \theta$ is the angle of the roadway; $r$ is the latent heat of water, $r=2501 \mathrm{~kJ} / \mathrm{kg} ; \varphi_{o}$ is the relative humidity of the air flow outside air duct; $B$ is the ram pressure of moist air, $\mathrm{Pa} ; \rho$ is the density of moist air, $\mathrm{kg} / \mathrm{m}^{3}$; $c$ is the air leakage volume per unit length, $\mathrm{kg} / \mathrm{m} \cdot \mathrm{s} ; d_{i 14}$ and $d_{i 56}$ are the moisture contents of the air flow inside air duct in front and back of air cooler respectively, $\mathrm{kg} / \mathrm{kg} ; k_{\tau}$ is the unstable heat transfer coefficient between air flow and surrounding rock, $\mathrm{kW} /\left(\mathrm{m}^{2} \cdot{ }^{\circ} \mathrm{C}\right) ; U$ is the circumference of the excavation roadway, $\mathrm{m} ; \varphi^{`}$ is the relative humidity average changing rate of the air flow outside the air duct; $\varphi$ is the relative humidity of the air flow; $p_{s o}$ is the saturated water vapor partial pressure, $\mathrm{Pa}$; $t$ is the temperature of air flow, ${ }^{\circ} \mathrm{C}$; other symbols ibid.

(3) For the excavation heading area between section 6 and section 7 , there are several heat sources including: the heat dissipation from the surrounding rock on the end face and the nearby tunnel, the heat dissipation from the mechanical and electrical equipment, the oxidative heat dissipation, the staff's heat dissipation. The air energybalance equation can be deduced as:

$$
\begin{aligned}
& M_{6}\left[C_{p}\left(26-t_{6 i}\right)+r\left(d_{6 o}-d_{6 i}\right)\right] \\
& =\overline{k_{\tau 67}} U L_{5}\left(t_{g u}-\frac{26+t_{6 i}}{2}\right)+k_{\tau 7} F_{m}\left(t_{g u}-\frac{26+t_{6 i}}{2}\right)+\sum Q_{m}
\end{aligned}
$$

$$
d_{6 o}=\varphi_{6 o} \cdot d_{26}
$$

where $M_{6}$ is the mass flow rate of dry air flow at section 6 , $\mathrm{kg} / \mathrm{s} ; t_{6 i}$ is the air temperature inside the air duct at section 6 , ${ }^{\circ} \mathrm{C} ; d_{6 i}$ and $d_{6 o}$ are the moisture contents of air flow inside and outside the air duct at section 6 respectively, $\mathrm{kg} / \mathrm{kg} ; \overline{k_{\tau 67}}$ is the unstable heat transfer coefficient from the air duct exit to the end face of the excavation roadway, $\mathrm{kW} /\left(\mathrm{m}^{2} \cdot{ }^{\circ} \mathrm{C}\right) ; k_{\tau 7}$ is the average unstable heat transfer coefficient on the end face of the excavation roadway, $\mathrm{kW} /\left(\mathrm{m}^{2} \cdot{ }^{\circ} \mathrm{C}\right) ; F_{m}$ is the area of the end face, $\mathrm{m}^{2} ; \sum Q_{m}$ is the sum amount of heat dissipation from other heat sources except surrounding rock, $\mathrm{kW} ; \varphi_{6 o}$ is the relative humidity of the air flow outside the air duct at section $6 ; d_{26}$ is the saturated humidity of air flow with $26^{\circ} \mathrm{C}, \mathrm{kg} / \mathrm{kg}$; other symbols ibid.

\subsubsection{Differential calculation of the air temperature}

The prediction mathematical model of air temperature is calculated with the finite difference method. The roadway and air duct from section 3 to section 6 are divided into (n-1) segments equally, and section 3-4 divided into $\left(\mathrm{m}_{1}-1\right)$ segments while section 5-6 divided into $\left(\mathrm{m}_{2}-1\right)$ segments. There are $2 \mathrm{n}$ nodes in amount, and $2 \mathrm{~m}_{1}$ nodes in section $3-4$ while $2 \mathrm{~m}_{2}$ nodes in section 5-6. The number of node in the excavation roadway is as shown in Figure 4.

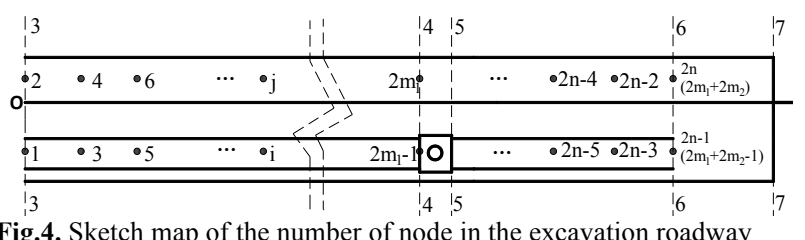

(1) It should be noted that there is no difference equation at node $2 \mathrm{~m}_{1}-1$, thus the energy-balance equation of the air flow inside the air duct is converted to the differential manner as:

$$
\begin{array}{r}
\left(\frac{M C_{p}}{\Delta x}-\frac{k \pi D}{2}\right) t_{i}+\frac{k \pi D}{2} t_{i+1}-\left(\frac{M C_{p}}{\Delta x}+\frac{k \pi D}{2}\right)_{i+2}+\frac{k \pi D}{2} t_{i+3}=M g \sin \theta \\
\left(i=1,3,5, \cdots, 2 \mathrm{~m}_{1}-3,2 \mathrm{~m}_{1}+1, \cdots, 2 \mathrm{n}-3\right)
\end{array}
$$


(2) Noted that there is no differential equation at node $2 \mathrm{~m}_{1}$, the derivative in energy-balance equation of the air flow outside air duct is approximately replaced with the finite difference quotient, then the equation is deformed as:

$$
\begin{aligned}
& -A_{2} t_{j-1}+\left(A_{2}+A_{4}+A_{5}+2 A_{1}\right) t_{j}-A_{2} t_{j+1} \\
& +\left(-2 A_{1}+A_{2}+A_{4}+A_{5}\right) t_{j+2}=2 A_{3}+2 A_{4} t_{g u}+2 A_{6}(10) \\
& \left(j=2,4,6, \ldots, 2 \mathrm{~m}_{1}-2,2 \mathrm{~m}_{1}+2, \ldots, 2 \mathrm{n}-2\right) \\
& A_{1}=\frac{M}{\Delta x}\left(C_{P}+r \frac{130.93 \varphi_{o}}{B-3066.8}\right) \quad A_{2}=k \pi D+C_{P} \frac{\rho c}{1+d_{i}} \\
& A_{3}=\frac{\rho c}{1+d_{i}} r d_{i}-M g \sin \theta \quad A_{4}=k_{\tau} U \\
& A_{5}=\frac{130.93 r}{B-3066.8}\left(\frac{\rho c}{1+d_{i}} \varphi_{o}+M \varphi^{\prime}\right) \quad A_{6}=\frac{2066.5}{210.5} A_{5}
\end{aligned}
$$

(3) Ignoring the size of air cooler, it can be deduced that:

$$
t_{2 m_{1}}=t_{2 m_{1}+2}
$$

(4) For the excavation roadway from section 3 to section 6 , the boundary conditions can be deduced as:

$$
t_{1}=t_{3 i}, \quad t_{2 n}=26, \quad t_{2 n-1}=t_{6 i}
$$

Simultaneous equations from equation (9) to equation (12) constitute a system of linear equations with $2 \mathrm{n}$ equations in amount, and based on this, the air flow temperature of each node in the excavation roadway can be obtained. The temperatures of node $2 \mathrm{~m}_{1}-1$ and $2 \mathrm{~m}_{1}+1$ inside the air duct in front and back of the air cooler are the temperatures needed for the calculation of chilling requirement. Due to the heat and moisture exchange effect of the air cooler, the air flow humidity inside the air duct in front and back of the air cooler are no longer equal. Thus the iterative calculation must be carried out while calculating the system of linear equations. The moisture content of the air flow at section 1 can be seen as the initial value, and taking the saturated humidity corresponding to $t_{5 i}$ as the moisture content of the air flow inside the air duct from section 5 to section 6 , the above calculations is repeated until the desired accuracy.

\subsubsection{Calculation of chilling requirement}

According to the above analysis, ignoring the air leakage of the air cooler, the chilling requirement in the excavation roadway with air conditioning measures is equal to the product of the enthalpy difference and the mass flow rate of the air flow in front and back of the air cooler.

$$
Q=M_{4 i}\left(i_{4 i}-i_{5 i}\right)=M_{4 i}\left[C_{p}\left(t_{4 i}-t_{5 i}\right)+r\left(d_{4 i}-d_{5 i}\right)\right]
$$

where $M_{4 i}$ is the mass flow rate of the air flow inside air duct at section 4 and the mass flow rate of air flowing through the air cooler, $\mathrm{kg} / \mathrm{s} ; i_{4 i}$ and $i_{5 i}$ are the air enthalpy inside the air duct in front and back of the air cooler respectively, $\mathrm{kJ} / \mathrm{kg} ; t_{4 i}$ and $t_{5 i}$ are the air temperatures inside the air duct in front and back of the air cooler, ${ }^{\circ} \mathrm{C}$; $d_{4 i}$ and $d_{5 i}$ are the air humidity inside the air duct in front and back of the air cooler, $\mathrm{kg} / \mathrm{kg}$; other symbols ibid.

From above analysis, the air humidity inside the air duct at section 4 is equal to the humidity at local fan entrance. The air temperature inside the air duct at section 4 and section 5 and the air humidity at section 5 can be calculated with the prediction model. Given the mass flow rate of air flowing through the air cooler, the chilling requirement in the excavation roadway with air conditioning measures can be obtained.

3.3 Design of the calculation program of chilling requirement in excavation roadway

Based on the prediction mathematical model and the boundary conditions, a computer program is edited to calculate the chilling requirement in the excavation roadway with air conditioning measures. Program chart is as shown in Figure 5.

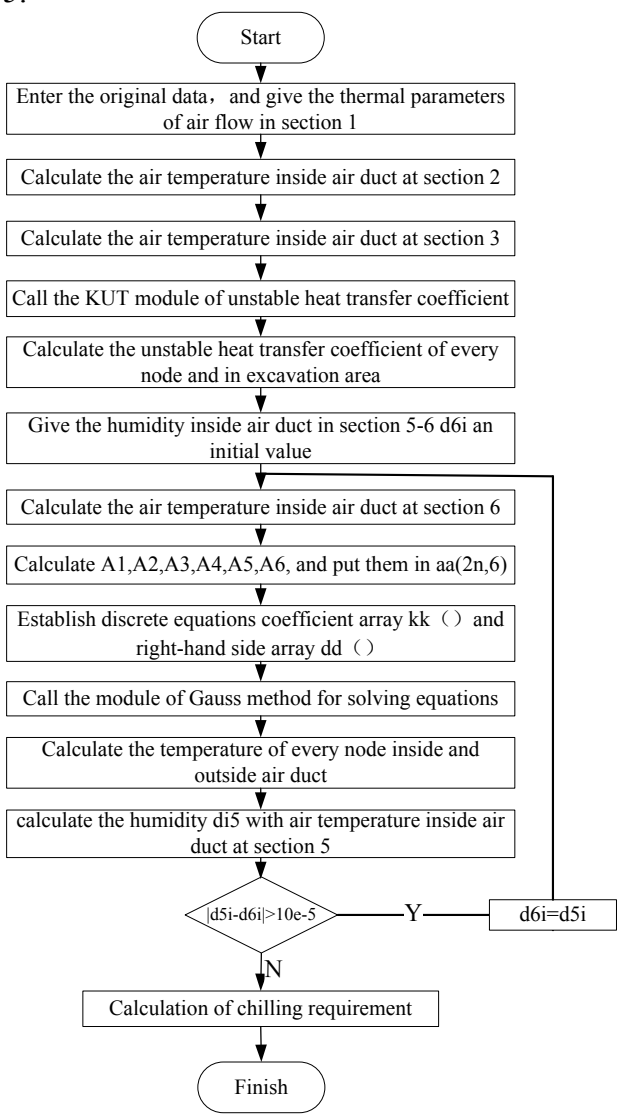

Fig.5. Program chart of the chilling requirement calculation

\section{Results}

According to the realistic circumstance of an excavation roadway, if the air temperature in the excavation heading area needed to be controlled below $26{ }^{\circ} \mathrm{C}$, the chilling requirement and the air flow temperature variation inside and outside air duct can be obtained by the prediction program. The calculated temperatures variation of the air flow inside and outside air duct are as shown in Figure 6. A is for the local fan entrance, B is for the air duct entrance, and $\mathrm{C}$ is for the excavation roadway entrance.

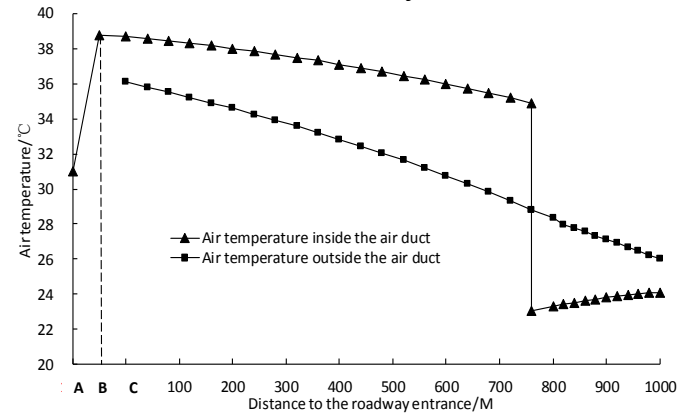

Fig.6. Curve of the air temperature variation inside and outside air duct 
Given the air temperature at local fan entrance is $31^{\circ} \mathrm{C}$, in order to achieve the requirement of 'Coal Mine Safety Regulations' about the environmental temperature in working face, the calculated minimum chilling requirement in this circumstance is $346.8 \mathrm{~kW}$ in amount. The temperature in the excavation heading area can be controlled within $26^{\circ} \mathrm{C}$ if the air temperature from the air cooler dropped to $22^{\circ} \mathrm{C}$, and the environmental temperature can also be reduced to less than $28^{\circ} \mathrm{C}$ within the scope of $200 \mathrm{~m}$ from the end face. Considering the loss of the refrigeration system and the heat transfer efficiency of the air cooler, the surplus coefficient is designed as 1.2 , and the equipped cooling capacity in working face should be no less than $416.2 \mathrm{~kW}$. Therefore, a RWK450 air cooler with the rated cooling capacity of $450 \mathrm{~kW}$ is selected for providing the cooling capacity and set up at one side of the roadway and $200 \mathrm{~m}$ from the end face.

After installing and using the selected air cooler, the thermal parameters of the air flow in the excavation roadway are measured, and results show a good application effect: the environmental temperature is reduced to $24.5^{\circ} \mathrm{C}$, within the scope of $120 \mathrm{~m}$ and $300 \mathrm{~m}$ from the end face, the temperature are reduced to less than $26^{\circ} \mathrm{C}$ and $28^{\circ} \mathrm{C}$ respectively. For comparison, the temperature around the excavation heading area in the prediction program of air temperature is adjusted to $24.5^{\circ} \mathrm{C}$, and the prediction is conducted while the in-situ air temperature of fan entrance is $31^{\circ} \mathrm{C}$, the comparison between calculated result and measured data is as shown in Figure 7.

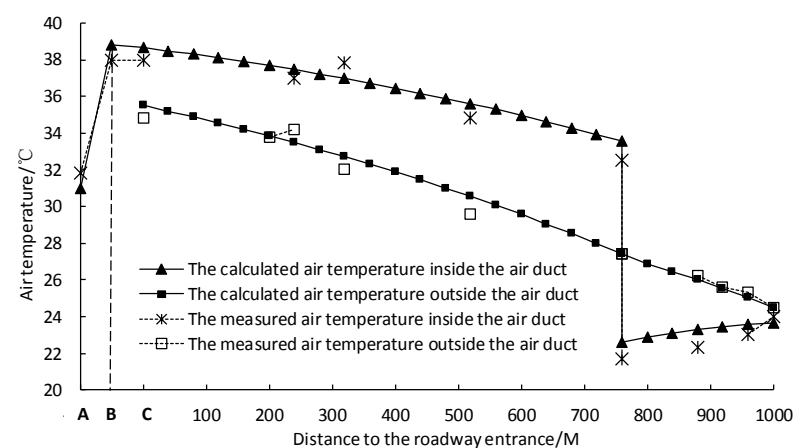

Fig.7. Contrast curve of the calculated and the measured air temperatures inside and outside air duct

It can be seen that the variation curve of the calculated air temperature is smooth, complying with the continuous variation of air flow temperature. The air temperatures inside and outside air duct both change non-linearly. The temperature of the air flow being inhaled into air duct is higher than the temperature in roadway, because the temperature rise caused by local fan is large. Thus the air flow inside air duct gives out heat and then cooling down, the temperature is still too high for the ventilation of working face, and an air cooler is needed to cool the air flow. Compared with the measured thermal parameters of the air flow, the results in this paper are consistent with the realistic circumstances which indicate that prediction method and calculating procedure are both reliable.

\section{Conclusions}

According to the temperature field of surrounding rock in the excavation roadway with moving boundary, introducing the moving coordinate system, the unsteady heat conduction differential equation is converted to the steady state one. Thus, the complex calculation of the heat dissipation from the surrounding rock in the excavation roadway is greatly simplified.

The heat dissipating capacity of the surrounding rock in the excavation roadway is calculated with the unstable heat transfer coefficient by calculating the temperature field, thus provide the basic data for the prediction of the air temperature and calculation of the chilling requirement.

According to the ventilation system in the excavation roadway with air conditioning measures, the energy-balance equations of the air flow inside and outside air duct are set up separately. Thus, the differential calculation model of air temperature is established considering the heat dissipation from the surrounding rock and the coupling effect of the air flow inside and outside the air duct.

Using the self-developed calculation program of chilling requirement in the excavation roadway with air conditioning measures, the cooling amount can be obtained with the air enthalpy inside the air duct in front and back of air cooler.

With the calculated results applied to field trial, the air cooler is reasonably selected, and a good cooling effect has been observed. The prediction method and calculation procedure are both reliable, thus provide the scientific theory and method for designating the air conditioning measures in the excavation roadway with high temperature.

\section{Acknowledgements}

This work was supported by the National Natural Science Foundation of China under the project No. 51174211.

\section{References}

1. Yu, H. C., "Mine geothermal and thermal damage control", China Coal Industry Publishing House, China, Beijing, 1991.

2. Voss, J., "Mine climate", China Coal Industry Publishing House, China, Beijing, 1989.

3. Xin, S., "Prevention and cure of thermal hazard in mines", China Coal Industry Publishing House, China, Beijing, 2011.

4. Шербань, А. H., "Mine Cooling Guide". China Coal Industry Publishing House, China, Beijing, 1982.

5. Yan, R. L., \& Hou, X. W., "Mine air conditioning technology", China Coal Industry Publishing House, China, Beijing, 1994.

6. Cen, Y. Q., \& Hou, Q. Z., "Mine Thermal Environmental Engineering", Wuhan Institute of Technology Press, China, Wuhan, 1989.

7. Starfield, A. M., \& Bleloch, A. L., "A new method for the computation of heat and moisture transfer in partly wet airway", $J$. S. Afr. Ins.t Min. Met, 83 (11), 1983, pp. 263-269.
8. Uchino, K., \& Inoue, M., "New practical method for calculation of air temperature and humidity along wet roadway-the influence of moisture on the underground environment in mines (2nd Report)", Journal of the Mining and Metallurgical Institute of Japan, 102 (6), 1986, pp. 353-357.

9. Uchino, K., \& Inoue, M., "Improved practical method for calculation of air temperature and humidity along a roadway under complicated conditions-the influence of moisture on the underground environment in mines (3rd Report)", Journal of the Mining and Materials Processing Institute of Japan, 106 (1), 1990, pp. 7-12.

10. Hu, T. Y., "Methods for calculation of air temperatures along ventilation ducts in the driving face", Journal of Huainan Mining Institute, 14 (3), 1994, pp. 34-39. 
11. Sasaki, K., Miyakoshi, H., and Mashiba, K., "Analytical system for ventilation simulators with skyline modal pressure method and practical estimate system for underground mine air-conditioning", 26th Proceedings of the Application of Computers and Operations Research in the Mineral Industry, 1996, pp. 393-399.

12. Qu, F. \& Qin Y. P., "Effects of concentrating production on the climate and refrigerating capacity of coal face in hot mine", Shanxi Mining Institute Learned Journal, 14 (4), 1996, pp. 341-349.

13. Qu, F. \& Qin Y. P., "Approaching the reasonable arrangement of mining faces in hot mine from dropping the temperature", Shanxi Mining Institute Learned Journal, 15 (3), 1997, pp. 261-267.

14. Bluhm, S. J., Biffi, M. \& Wilson, R. B., "Optimized cooling systems for mining at extreme depths", CIM bulletin, 93 (1036), 2000, pp.146-150.

15. Gao, J. L., Uchino, K., \& Inoue, M., "Prediction of climatic conditions in developing roadway with forcing auxiliary ventilation system. Control of thermal environmental conditions in locally ventilated working place. (2nd Report)", Journal of the Mining and Materials Processing Institute of Japan, 118 (2), 2002, pp.69-74.

16. Gao, J. L., \& Wei, P. R., "Numerical simulation of the thermal environment at working face of driving airway", Journal of China Coal Society, 31 (2), 2006, pp. 201-205.

17. Li, R., "Study on heat-calamity forecast model in driving roadway of deep shaft", Master thesis in safety technology and engineering, Xi'an University of Science and Technology, China, Xi`an , 2009.

18. Qi, P., "Heat exchange analysis of HEMS cooling system in Jiahe deep mine", Ph.D. thesis in geotechnical engineering, China University of Mining \& Technology (Beijing), China, Beijing, 2011.
19. Guo, P. Y., \& Zhu Y. Y., "Back-analysis algorithm of cooling load in deep mines", Journal of Mining \& Safety Engineering, 28 (3), 2011, pp. 483-487.

20. Ji, J. H., Liao, Q., Hu, Q. T., Chu, Z. X., Zhang, X. J., \& Gong, L. $\mathrm{P}$., "Heat transfer characteristics of driving face in heat harm mine", Journal of China coal society, 39 (4), 2014, pp. 692-698.

21. Qin, Y. P., Qin, F. H., \& Xu, G. F., "Prediction of air temperature in heading face and calculation of cooling amount", Journal of China Coal Society, 23 (6), 1998, pp. 611-615.

22. Wu, Q., Qin, Y. P., Guo, L. \& Wu, Q. Y., "Calculation of the heat emitting from the wall rock at drifting face with finite element method", China Safety Science Journal, 12 (6), 2001, pp.33-36.

23. Qin, Y. P., Dang, H. Z., \& Qu, F., "Dimensionless analysis on heat dissipation of rock surrounding in coal face", Journal of China coal society, 23 (1), 1998, pp. 62-66.

24. Qin, Y. P., Qin, F. H., \& Yu, M. X., "The study of heat transfer in rock surrounding coal face with finite element method", Journal of Liaoning Technical University (Natural Science). 18 (4), 1999, pp. 342-346.

25. Wang, Y. H., "Study on simulation of spontaneous combustion in goaf on the moving coordinate with finite volume method", $\mathrm{Ph} . \mathrm{D}$. thesis in safety technology and engineering, China University of Mining \& Technology (Beijing), China, Beijing, 2009.

26. Qin, Y. P., Wang, J., Hao, Y. J., Liu, W., \& Kong S., "Dimensionless analysis for heat dissipation from surrounding rock in roadway", Mining and Metallurgical Engineering, 33 (3), 2013, pp. 5-7.

27. Qin, Y. P., Jia, J. Y., Liu, W., \& Yang, X. B., "Four finite volume schemes for heat transfer problems", Journal of Liaoning Technical University (Natural Science), 32 (6), 2013, pp. 763-767. 